\title{
Economías populares, economías plurales
}

\section{Sobre la organización gremial de los trabajadores costureros en Buenos Aires, Argentina}

\section{Dolores Señorans ${ }^{1}$}

\author{
1 Instituto de Ciencias Antropológicas, Facultad de Filosofía y Letras, Universidad de Buenos Aires, Ciudad \\ Autónoma de Buenos Aires, Argentina \\ ORCiD: 0000-0002-4352-8863 \\ Correo electrónico: dolisenorans@gmail.com
}

Recibido

septiembre de 2019

Aceptado

marzo de 2020

doi: $10.34096 /$ cas.i 151.8240

\section{Palabras clave}

Economía Popular; Trabajadores costureros; Organización gremial; Economía; Reproducción de la vida

\section{Popular economies, plural economies. On the trade union organi- sation of garment workers in Buenos Aires, Argentina}

\begin{abstract}
This article is based on an ethnographic research developed together with the Textile Branch of the Movement of Excluded Workers (MTE) that belongs to the Confederation of Workers of the Popular Economy (CTEP), in the Metropolitan Area of Buenos Aires, Argentina. I show that the popular economy is plural in the sense that it assembles and builds on relationships usually considered "non economical" (family, couple, community and political ties). I analyse how this plurality was processed to create a form of trade union organisation that articulated productive work with the
\end{abstract}

\section{Key words}

Economy; Garment Workers; Trade Union Organization; Economy; Reproduction of life 
development of collective forms for the reproduction of life. I argue that the popular economies' plural character as a condition and potential allows to emphasize the value of its everyday production and to call into question the preconceptions and stigmas associated to its workers.

\section{Economias populares, economias plurais. Sobre a organização sindical dos trabalhadores costureiros em Buenos Aires, Argentina}

Palavras-chave

Economia Popular; Trabalhadores costureiros; Organização sindical; Economia; Reprodução da vida
1. Utilizo comillas para citar el discurso directo de mis interlocutores o de los autores consultados y cursiva para categorías sociales.

\section{Resumo}

Este artigo baseia-se numa investigação etnográfica desenvolvida junto ao Ramo Têxtil do Movimento de Trabalhadores Excluídos (MTE), pertencente à Confederação de Trabalhadores da Economia Popular (CTEP), na Área Metropolitana de Buenos Aires, Argentina. Tento mostrar que a economia popular é plural no sentido de que mistura e se constrói a partir de relações geralmente consideradas "não econômicas" (a família, o casal, os vínculos comunitários e políticos). Quero analisar o modo em como esta pluralidade foi processada para criar uma forma de organização sindical que articulou o trabalho produtivo com o desenvolvimento de formas coletivas de reprodução da vida em sentido amplo. Sustento que o caráter plural como condição e potencialidade das economias populares permite sublinhar o valor da sua produção cotidiana desafiando os preconceitos e estigmas que pesam sobre os seus trabalhadores.

\section{Introducción}

Ese mediodía había llegado un poco temprano con algunos afiches bajo el brazo. Todavía el movimiento de la esquina de Avenida Corrientes y Anchorena era el de un día normal. Allí, y justo en la entrada de un shopping, se reuniría una media hora más tarde una multitud de costureros y costureras, vendedores y vendedoras ambulantes portando banderas y pancartas. A las 12 en punto llegó Fany, ${ }^{1}$ presidenta del Polo Textil Miró y de la Federación de Costureros de la Confederación de Trabajadores de la Economía Popular (CTEP). Oriunda de Itacurubí de la Cordillera, Paraguay, Fany lleva su largo cabello recogido en un nutrido rodete que se ha vuelto icónico: su perfil con el rodete y sentada en la máquina de coser la llevó a ser el símbolo de los costureros en la bandera del Movimiento de Trabajadores Excluidos (MTE) del que forma parte.

Mientras otros iban llegando, Fany me cebó unos mates y escribimos una consigna en los afiches para repartir entre algunos de los presentes: "Unidad de los costureros y ambulantes". El comunicado de la convocatoria había llegado el día anterior por WhatsApp y explicaba que esta concentración frente a un local de la marca Nike buscaba denunciar "las ganancias exorbitantes de esta multinacional a costa de la superexplotación de los trabajadores textiles y la persecución de los vendedores ambulantes" y cerraba: "El trabajo no es delito, es un derecho". Tan solo unos días antes, seis vendedores ambulantes de origen senegalés y tres militantes de la CTEP habían sido detenidos en el barrio de Constitución en el marco de un operativo policial que buscó decomisar su mercadería y despojarlos de sus medios de trabajo. Horas después fueron liberados gracias a una masiva convocatoria en las puertas de la comisaría. 
Esta movilización realizada en octubre de 2018 resulta ilustrativa de un primer sentido de pluralidad expresado en la construcción política de la CTEP. Creada en 2011, la CTEP es un sindicato que nuclea a las y los trabajadores de la economía popular: cartoneros, costureros, vendedores ambulantes, cooperativistas y horticultores, entre otros. La principal demanda de la CTEP es el reconocimiento de derechos laborales básicos para estos trabajadores -aportes jubilatorios, vacaciones, obra social, etc.- en tanto sector de la clase obrera sin posibilidades de acceder a un empleo asalariado y estable. Un punto nodal de esta demanda radica en el reconocimiento de que la producción de este conjunto heterogéneo de trabajadores no asalariados forma parte de las cadenas de valor de la economía "real", aun cuando sus integrantes están excluidos de los sistemas de protección social. Así, este sindicato busca resaltar que la economía popular no constituye un sector aislado de los procesos de acumulación del capital, y destaca las formas diversas y particulares que asumen la explotación, el despojo y la persecución de sus trabajadores. En este sentido, la categoría de economía popular expresa una apuesta por construir una reivindicación común a partir de formas de trabajo y experiencias de vida plurales. Tal como señaló María Inés Fernández Álvarez (2020), la CTEP ha convertido la creciente heterogeneidad de la clase trabajadora de la Argentina contemporánea en una potencialidad para la organización política y gremial. De allí que ha sido definida como "el otro movimiento obrero" (Abal Medina, 2018), en la medida en que su construcción política busca el pleno reconocimiento de sus integrantes como trabajadores y su institucionalización como sindicato (Bruno, Coelho y Palumbo, 2017; Muñoz, 2019). En este marco, algunos autores sostuvieron que su progresivo acercamiento con otros sindicatos y la CGT constituye una estrategia de superación de la fragmentación de la clase trabajadora (Natalucci y Morris, 2019).

Estos debates resuenan con una preocupación a nivel global en torno a la reconfiguración de las clases trabajadoras. Numerosos estudios han señalado la creciente heterogeneidad de los regímenes laborales contemporáneos. En esta dirección, algunos autores cuestionaron la predominancia actual -pero también histórica- del trabajo asalariado como la "norma" en todo el mundo. Esta literatura ha propuesto, por un lado, expandir la conceptualización de las clases trabajadoras más allá de su asociación con el fordismo (Kalb, 2015; Fernández Álvarez, 2020) y han problematizado las categorías de marginalidad, informalidad y exclusión que desde los años sesenta dominaron los estudios sociales sobre todos aquellos trabajadores que no se ajustan a dicha norma (Denning, 2011; Munck, 2013; Carbonella y Kasmir, 2015). Tal como señaló Michael Denning en su definición de las "vidas sin salario": "Proletario no es un sinónimo de trabajador asalariado, sino de desposeimiento, expropiación y dependencia radical del mercado" (2011, p. 79). Así, algunos autores han puesto de relieve las múltiples formas de desposesión que afectan la vida de los trabajadores sin salario en todo el mundo (Carbonella y Kasmir, 2015; Gago y Mezzadra, 2015).

Este artículo se propone contribuir a la problematización de la condición de asalariado como "norma" -y del trabajo remunerado como medio principal de vida- a partir del análisis de un segundo sentido de pluralidad condensado en la experiencia de la CTEP. Si en primer término afirmé que se trata de una organización plural en la medida en que reúne a un conjunto heterogéneo de trabajadores no asalariados, aquí quiero destacar que su carácter plural también se revela en el hecho de que su construcción cotidiana se asienta sobre las múltiples formas en que estos trabajadores construyen formas de "ganarse la vida". Recuperando los resultados de una investigación etnográfica junto a trabajadores costureros migrantes que integran la Rama Textil del MTE-CTEP, buscaré mostrar que la economía popular es plural en el sentido de que mixtura y se construye a partir de relaciones usualmente consideradas "no económicas" (la familia, la pareja, los vínculos comunitarios o políticos). En segundo lugar, quiero analizar el modo en que esta pluralidad fue procesada para crear una forma de organización gremial que articula el trabajo productivo con el desarrollo de formas colectivas de reproducción 
de la vida en un sentido amplio. Este análisis se apoya en la propuesta de Susana Nartozky y Niko Besnier (2014) de examinar la multiplicidad de formas en que las personas se "ganan la vida". Estos autores nos invitan a considerar no solo el trabajo remunerado y los intercambios mercantiles, sino también una variedad de formas de aprovisionamiento, cuidado, relaciones sociales y de confianza que los modelos económicos hegemónicos consideran marginales o "atrasados". Su reflexión se apoya en tres tradiciones analíticas para repensar la "economía": la economía política, la economía moral y la economía feminista. Así, ponen de relieve los procesos de diferenciación y acumulación del capital, el valor del trabajo no remunerado y los múltiples marcos de referencia que subyacen a las prácticas y relaciones económicas. En términos más amplios, esta propuesta busca interrogar cómo las personas construyen "vidas que valen la pena ser vividas" a partir de experiencias situadas y proyectando expectativas de futuro (de L'Estoile, 2014; Nartozky y Besnier; 2014). A partir de estos aportes, mi análisis busca problematizar aquello que se entiende por "economía" -y otras categorías asociadas, como "cálculo", "valor", "capital" o "producción"- en este universo etnográfico atendiendo a la pluralidad de formas de acción social, intercambios y relaciones sociales que dan forma a la economía popular.

Este trabajo recupera resultados de mi investigación doctoral y posdoctoral sobre prácticas de militancia y organización colectiva en la economía popular en el Área Metropolitana de Buenos Aires. Desarrollé el trabajo de campo en dos períodos: entre julio y diciembre de 2016, y desde abril de 2018 hasta la fecha. Mi investigación se nutre de los diálogos y el trabajo compartido junto a quienes integramos un proyecto de investigación más amplio, centrado en el estudio etnográfico de las prácticas de organización colectiva que trabajadores no asalariados llevan adelante para garantizar la producción y reproducción de la vida. Asimismo, en consonancia con el enfoque y la metodología propuestos por el equipo que integro, he desarrollado mi propio trabajo desde una perspectiva colaborativa, lo que implica producir conocimiento desde el compromiso y no desde la instauración de una distancia afectiva, política o profesional entre el investigador y las personas con quienes trabaja (Fernández Álvarez y Carenzo, 2012).

En la primera parte de este artículo, me detengo en el modo en que costureros y costureras me han relatado su trayectoria migratoria y sus inicios y experiencias en la industria de la confección de indumentaria. Focalizaré en cómo el vínculo con parientes, vecinos y paisanos los introdujo al trabajo en el sector, pero también les permitió crear talleres familiares en sus domicilios, impulsados por expectativas de "independencia", "superación" o "progreso". Luego, analizaré el modo en que dichos vínculos -que constituyen un recurso capitalizable para las cadenas de valor de la industria- se convirtieron también en condición de posibilidad para el desarrollo de una organización gremial que buscó generar trabajo con derechos. Me detendré en cómo se desarrollaron espacios colectivos de trabajo -los "polos textiles"- que recuperaron y reorientaron la pluralidad de prácticas, conocimientos, expectativas y relaciones que previamente habían marcado su inserción en la industria textil tercerizada. Por último, quiero proponer que la pluralidad como condición y potencialidad de las economías populares permite subrayar el valor de su producción cotidiana y cuestionar los prejuicios y estigmas con los que suele desvalorizarse a sus trabajadores.

\section{De talleres, familias, paisanos y progresos}

La voz de Margarita es pausada pero firme; su tono, dulce, pero el contenido, agrio. Estamos sentadas al costado de la enorme mesa de corte que se ubica justo en el centro de la Cooperativa Villa Victoria, de la que es presidenta. "Hay mucho más sobre cómo llegamos y nos superamos. Yo soy del campo indígena, apenas sabía hablar castellano cuando me fui de mi pueblo", me cuenta para dar inicio a una charla que tiene como 
excusa un pequeño texto que escribí contando su vida. Decide empezar por Villa Victoria. Al igual que la cooperativa -y justamente por eso- así se llama el barrio en el que nació en Machacamarca, un pueblo rural cercano a Oruro, Bolivia. En su celular me muestra fotos de su padre, sus ovejas, y un video en la que se la ve cargando en sus espaldas algunas pertenencias mientras atraviesa el campo caminando. "Para llegar a casa de mis padres son seis horas caminando así”, aclara mientras el audio del video trae el viento y la inmensidad del campo boliviano a un galpón inundado por el repiqueteo de máquinas de coser en Villa Fiorito. Si bien lo recuerda con cariño y vuelve a menudo de visita, Margarita abandonó el campo a sus dieciocho años para ir a Oruro. Allí conoció a su marido y nacieron sus dos primeras hijas. Allí también aprendió el oficio con el que se ganaría la vida en adelante: aprendió a "costurar".

En 1995 llegó a Buenos Aires con su marido y sus hijas mayores. Habían venido de visita a casa de su hermana y su cuñado. Se quedaron con ellos unos meses y, mientras tanto, Margarita los ayudaba en su taller de costura. Al poco tiempo decidieron instalarse en Argentina, pero como no podían quedarse en casa de su hermana, ambos aceptaron trabajar en un taller de un paisano en Flores. Fueron dos años con jornadas laborales que se extendían hasta altas horas de la noche a cambio de un magro sueldo, comida y un techo para toda la familia. Aquella experiencia marcó el modo en que proyectaría su trabajo en el futuro: "Aquí la gente es muy mala. Yo por eso digo, yo no voy a ser como ellos, cuando llegué y trabajé con mis paisanos mismos, te hacen trabajar hasta la una, hasta las dos de la mañana". El recuerdo es doloroso y no puede contener las lágrimas: "Yo al principio no lo creía, pero lo viví. Nos trataban mal, mis hijos estaban afuerita jugando" (Registro de Campo, Margarita, Buenos Aires, 3/5/2019).

Cansados de esa experiencia, decidieron mudarse. Ahorraron lo suficiente para comprar sus primeras máquinas y alquilaron una piecita en el barrio porteño de Flores. Así fue que comenzaron a trabajar en su propia casa cosiendo los "cortes" que les proveían otros paisanos conocidos. La familia se amplió con la llegada de tres hijos más y la piecita fue quedando pequeña. En 2006, la hermana de Margarita les avisó que un nuevo barrio producto de una toma de tierras estaba iniciándose y que podía ser que "hubiera un terrenito para comprar". Para acceder a comprar el lote recibieron ayuda económica de sus parientes. Tras algunos años, transformaron la casilla de madera que venía con el lote en una casa de losa de dos plantas donde vive hasta el día de hoy junto a sus hijos. La familia siempre se mantuvo dentro del rubro textil, pero fueron desarrollando distintas tareas en la cadena. Desde hace diez años, Margarita se dedica también a la venta, una actividad en la que tenía experiencia porque en Oruro había tenido su propia tienda de ropa. Hasta hace algunos años su marido cortaba y "costuraba" algunas prendas en su casa, que ella luego vendía. Destaca que desde entonces trabaja "por su cuenta": "Yo me costuro y me vendo, no me aprovecho del trabajo de otros” (Registro de Campo, Margarita, Buenos Aires, 3/5/2019).

La trayectoria de Margarita y su familia se asocia a la de tantos otros compatriotas de países vecinos que llegaron a la Argentina con la esperanza de mejorar sus vidas y las de sus familias. En particular, las colectividades paraguaya y boliviana son las más numerosas de la población migrante residente en Argentina. ${ }^{2}$ Desde 1960, estas colectividades migrantes se asentaron en el Área Metropolitana de Buenos Aires y, en virtud de una histórica segmentación del mercado de trabajo, se insertaron en sectores con elevados índices de trabajo informal, principalmente en los de la construcción, el servicio doméstico, la producción hortícola o la confección textil (Pacecca y Courtis, 2008). En efecto, algunos analistas propusieron la noción de "economías étnicas" para definir a estos sectores productivos desarrollados por migrantes que emplean a su vez a integrantes de la propia colectividad y cuya viabilidad económica depende del uso intensivo de la mano de obra (Halpern, 2005; Benencia, 2009).
2. Según el censo nacional de 2010, para ese año residían en nuestro país un total de 550.713 personas de origen paraguayo y 345.272 de origen boliviano, sobre un total de migrantes de países limítrofes y Perú de 1.805.957 (INDEC). Cabe destacar que ambas colectividades registraron un incremento de residentes en Argentina respecto del año 2001, momento en el que se registraban 325.046 y 233.464 personas respectivamente. Dicho incremento ha sido asociado a la reactivación económica posterior al 2003. Ver Calvelo (2012). 
3. En este incendio, ocurrido el 30 de marzo de 2006 en un taller ubicado sobre la calle Luis Viale, fallecieron una mujer embarazada y cinco niños. En 2016, Luis Sillerico y Juan Manuel Correa, encargado y capataz respectivamente, fueron condenados a 13 años de prisión por ser coautores del delito de reducción a la servidumbre.

4. El desarrollo de la industria en Argentina no ha sido una excepción respecto de las tendencias globales en el sector. Numerosos estudios han analizado la evolución reciente de la industria de la confección de indumentaria en todo el mundo, y destacan los cambios en las relaciones capital-trabajo a partir de la relocalización de la producción hacia regiones con costos laborales más bajos - principalmente en Asia-, la flexibilización del trabajo y el uso extensivo de la tercerización (Collins, 2007; Brooks, 2015; Campbell, 2018).
En particular, la confección de indumentaria ha sido objeto de un intenso debate público, político y académico. En 2006, el trágico incendio de un taller ubicado en la Ciudad de Buenos Aires ${ }^{3}$ puso en el centro de la atención pública las peligrosas condiciones de trabajo en el sector. En los años noventa se intensificó un proceso de "desverticalización" y "tercerización” de la confección de indumentaria hacia talleres no registrados, conocidos como "talleres clandestinos" (Adúriz, 2009; Lieutier, 2010; Montero, 2012). Al igual que en otras ramas de la industria, las políticas económicas neoliberales implementadas en aquellos años -en particular, el incremento de las importaciones y la paridad peso-dólar- produjeron una fuerte contracción de la producción, despidos y el cierre de establecimientos industriales (Salgado, 2012). En este contexto, las marcas y empresas transfirieron la confección hacia talleres no registrados como parte de una estrategia para garantizar menores costos productivos, concentrándose en las áreas más rentables del proceso: el diseño, marketing y comercialización (Arcos, 2013). ${ }^{4}$ Posteriormente, la reactivación económica evidenciada entre 2003 y 2008 conllevó un aumento de la producción local que acompañó el crecimiento del consumo interno de indumentaria, pero sin que se viera modificado el modelo productivo.

En estos talleres textiles, un patrón o capataz emplea a un grupo de trabajadores migrantes por una exigua remuneración y un techo donde vivir con sus familias. Al igual que Margarita, muchos me han relatado con amargura sus experiencias en los talleres. El hacinamiento, la escasa comida, el control estricto de los tiempos de vida y de trabajo, los malos tratos, el no poder salir, los pagos adeudados que nunca cobraron. Para los costureros y costureras, esta experiencia marcó sus vidas de un modo difícil de olvidar. Se trataba de una vivencia que volvía insistentemente al presente, a veces como recuerdo, otras veces como fantasma. “¿¡Cómo que nunca escuchaste hablar del costurero sin cabeza!?", exclamó Luisa -costurera de la Cooperativa 23 de Marzo- durante un almuerzo. Ante mi negativa, me explicó:

Es un mito del tiempo de la explotación, cuando llegaron los primeros paisanos a Buenos Aires a trabajar en los talleres y te explotaban; no te dejaban salir. Se aparece de noche y te mira, por eso nos da miedo estar trabajando solas en el taller. Es un alma en pena, era un hombre que trabajaba en un taller y como se quejó porque le adeudaban su paga, el patrón le cortó la cabeza. Por eso anda por los talleres y asusta a los costureros que están solos trabajando de noche. (Registro de campo, Luisa, Buenos Aires, 11/4/ 2019)

Aquella experiencia que esta trabajadora describía como el "tiempo de la explotación" fue abordada y conceptualizada en el debate público y político a partir de la categoría de "trabajo esclavo". Así, la denuncia de las graves condiciones de labor en el sector tuvo como correlato la cristalización una una mirada estereotipada sobre estos trabajadores, que podemos condensar en la noción de víctima-esclavo, una mirada que evoca imágenes de pasividad y sumisión y que refuerza la estigmatización de las colectividades migrantes. Sin embargo, como indican las historias de Margarita y las de tantos otros costureros que conocí en estos años, los trabajadores se apoyaron en la familia y en los vínculos con paisanos para construir otras formas de trabajo vivenciadas como autónomas o independientes, una aspiración activamente construida como contracara de sus dolorosas experiencias previas en los talleres.

A este respecto, la historia de Liders resulta ilustrativa. Liders, que hoy es presidente de la Cooperativa 23 de Marzo, llegó a la Argentina de Santa Cruz de la Sierra, Bolivia, hacia fines de los años noventa. Allí había trabajado toda su vida como chofer de micros y llegó a liderar como secretario general un sindicato de choferes durante diez años. Tras invertir todo su dinero en un negocio frustrado, decidió que era tiempo de irse para empezar de nuevo. Les pidió dinero prestado a sus hermanos: "Yo decía, bueno 
yo me voy a Argentina, pero necesitaba un dinero para arrancar, y uno piensa que la familia es la que tiene que ayudar, así se hace, juntamos un poco y yo luego devuelvo". Sus hermanos se negaron y la ruptura de esa expectativa de ayuda por parte de la familia lo marcó con un profundo enojo. A pesar de todo, decidió viajar: "Me vine igual. Así sin nada, tenía plata pero que alcanzaba solo para el viaje" (Registro de Campo, Liders, Buenos Aires, 7/6/2018).

Una vez en Argentina, comenzó a buscar trabajo.

\begin{abstract}
Al principio me dieron a elegir, y tuve un tiempo ese trabajo que tienes que romper veredas y eso con el taladro, pero yo siempre había sido chofer, el cuerpo no está preparado para eso. Y lo otro era la costura. Así que al poco tiempo elegí eso. (Registro de campo, Liders, Buenos Aires, 7/6/2018)
\end{abstract}

En la construcción le pagaban 20 dólares por día, eran tiempos del 1 a 1, pero igual no le alcanzaba para pagar el alquiler y vivir. En cambio, en la confección, además de su magra paga, le daban lugar para vivir. El primer taller donde trabajó y vivió era en La Paternal. Allí conoció a su actual pareja, también costurera y migrante del Perú. Ambos vivían juntos en el taller y al poco tiempo nació su hija, que hoy tiene 18 años.

Durante sus primeros tiempos en el taller ganaba muy poco. En ese entonces era apenas ayudante. A los dos meses, confiado de que podía aprender, se sentó en una máquina y en poco tiempo comenzó a trabajar como costurero. Cuando nació su pequeña hija comenzaron a pensar en "independizarse":

No teníamos lugar, teníamos que dormir los tres en una cucheta, mi mujer y la bebé para un lado y yo con la cabeza para el otro. Ahí dije, si estos paisanos llegaron a tener todo esto ¿por qué yo no? (Registro de campo, Liders, Buenos Aires, 7/6/2018).

Así que ahorraron, compraron primero una máquina recta y luego una overlock. Se mudaron a Villa Celina, donde comenzaron a trabajar en su casa. Como no tenían collareta, ${ }^{5}$ llevaba las prendas preparadas para hacer las terminaciones a la casa de un paisano que se la prestaba. Así comenzaron a confeccionar a façon-es decir, a pedido de un tercero, dueño de los insumos- para marcas o fabricantes. Recibían las prendas o "cortes" para confeccionar a través de intermediarios -muchas veces, vecinos o conocidos de la colectividad- que se quedan con un porcentaje del costo por unidad.

Además, junto con su mujer y posteriormente su sobrina, Liders emprendió numerosas "producciones propias" para vender en ferias como La Salada. ${ }^{6}$ Para ello se valió del dinero obtenido de su participación en un pasanako junto con otros paisanos. El pasanako o pasanaku es una forma de ahorro y financiamiento colectivo muy utilizado por la colectividad boliviana, aunque también existe en otros países bajo diferentes denominaciones. El sistema consiste en que cada integrante aporta una suma fija de dinero mensual durante un período de tiempo, acorde con la cantidad de personas que integran el grupo, con el objetivo de conformar un fondo que luego es utilizado rotativamente por quienes lo conformaron (usualmente, una vez por mes). Con el dinero obtenido compró las telas necesarias. "En ese momento yo quería comprarme una camioneta”, me explicó, y continuó relatándome que al mismo tiempo, también sostenía junto a su mujer y otros vecinos un comedor comunitario en su barrio, en el que servían la merienda para casi 200 chicos. Así, sus palabras también exponen el modo en que la voluntad de progreso individual y familiar convive con formas de lucha y organización por el bienestar comunitario. $\mathrm{O}$, en otros términos, que las expectativas y proyecciones a futuro son también plurales y no se ajustan a la dicotomía entre el cálculo como maximización del beneficio individual y la apuesta por relaciones o construcciones comunitarias. En este sentido, atender al carácter plural de las
5. La collareta es una máquina de uso frecuente para la confección de prendas de tela de punto. Permite colocar cuellos y realizar las terminaciones de los dobladillos.

6. La Salada es el mayor y más famoso mercado popular de la Argentina. Allí se comercializan principalmente indumentaria, calzado y ropa de cama. 
expectativas permite poner en cuestión lo que Verónica Gago (2014) ha dado en llamar la "moralización" de las economías populares, es decir, la condena moral de las aspiraciones de progreso y autonomía esbozadas por los propios trabajadores.

Sin embargo, muchos me relataron el modo en que sus iniciativas se vieron frustradas por el peso de una desigualdad que no podía torcerse tan solo con la propia decisión o impulso. Así, las familias también compartieron y sufrieron los fracasos, algunos de ellos muy rotundos, en los que "perdieron todo". Tal fue el caso de doña Clara, costurera de Villa Victoria. Clara me relató que cuando llegó de Bolivia, hace casi 20 años, había trabajado en un taller textil. Esa experiencia había sido dura y, para salir de allí, su marido le propuso que iniciaran su propio negocio fabricando remeras deportivas. Consiguieron un préstamo para comprar las telas y las máquinas, pero la venta en la feria no fue bien y se quedaron con una gran cantidad de remeras y las deudas. $\mathrm{Al}$ respecto reflexionó: "En la feria, como en todo, el negocio está muy concentrado, no es fácil conseguir clientes para vender en cantidad porque otros puesteros ya tienen el negocio armado". Tiempo después, y a pesar de todo, volvieron a empezar "costurando" camperas por encargo.

Estas iniciativas -y el tesón con el que las construyeron y reconstruyeron- contrastan fuertemente con la noción de víctima-esclavo que cristalizó en el debate público sobre el sector de la confección mencionado previamente. Tal como reconocen y elaboran los propios trabajadores, no puede desconocerse que existen condiciones de trabajo marcadas por la explotación, el maltrato, las largas jornadas y la falta de derechos laborales. A pesar de ello, estas condiciones no son acríticamente aceptadas por los trabajadores -como se infiere de su caracterización como "esclavos"- sino que han sido activos en la búsqueda de un futuro mejor para sí mismos y sus familias. Y para ello se han apoyado en las relaciones construidas en sus trayectorias migratorias, sus vínculos de parentesco y comunitarios.

Numerosos estudios sobre los talleres textiles en Buenos Aires han destacado que las relaciones de parentesco, compadrazgo y vecindad constituyen tramas ineludibles para comprender la emergencia y proliferación de estos talleres y formas productivas (Rivera Cusicanqui, 2011; Gago, 2014; Castronovo, 2018). Se trata, por otro lado, de una cuestión que ha sido históricamente tematizada en los estudios antropológicos sobre sectores populares urbanos en América Latina. En su ya clásica obra titulada Cómo sobreviven los marginados, Larissa Lomnitz (1993) sostuvo que la "supervivencia" de los pobladores de una barriada de la ciudad de México se garantizaba a partir de la ayuda mutua y el intercambio recíproco de bienes y servicios al interior de la familia $o$ entre vecinos. La autora tomaba como punto de partida la oposición entre dos tipos o esferas de intercambio definidas por la antropología clásica: la economía de mercado y las redes de reciprocidad/ayuda mutua. Además, esta distinción de esferas también presupone una mirada moral que, tomando los términos propuestos por Viviana Zelizer (2009), delimita "mundos hostiles": de un lado, el cálculo, la competencia y el potencial aprovechamiento (mercado); del otro, la solidaridad desinteresada (la familia, los vecinos). En esta dirección, las historias relatadas muestran que, para los costureros y costureras, las relaciones familiares y comunitarias también contribuyeron a "hacer capital", invertir y desarrollar sus propias iniciativas. El modo en que la industria textil tercerizada se alimentó del trabajo en los talleres muestra que dichos vínculos tampoco son necesariamente armónicos, sino que pueden ser el anclaje de formas de explotación.

A continuación, desarrollo el modo en que estos trabajadores lograron transformar en base para la organización gremial esta pluralidad de prácticas, conocimientos, expectativas y relaciones que previamente habían marcado su inserción en la industria. Como veremos, este proceso de organización muestra que el trabajo que llevan adelante no es meramente de subsistencia, ni se vuelca solamente a alimentar las cadenas de valor 
de la industria, sino que les ha permitido luchar colectivamente por una vida mejor para sí mismos, sus familias y vecinos.

\section{"La casa para habitar, el polo para trabajar"}

"Estas no pueden ser", dijo Margarita con certeza mientras señalaba unas casas grandes y vistosas. Estábamos en el barrio de Lugano, buscando el lugar en el que nos reuniríamos con un grupo de trabajadores conocidos de su sobrino. Luego de caminar unos metros, en medio de los grandes chalets, identificamos el número que buscábamos. Estaba colgado en un portón negro y señalaba el ingreso a una vivienda mucho más modesta. "Ahora sí, es acá", indicó mientras tocaba a la puerta. Miguel nos abrió la puerta, adentro nos esperaban dos parejas, una mujer con sus hijas y un hombre con su hijo. Más tarde, nos contarían que vivían por la zona y trabajaban en sus casas con sus propias máquinas. Miguel y su mujer habían dispuesto una amplia ronda de sillas en la sala de estar, así que nos fuimos sentando. Andrea, militante de la rama textil del MTE, dio inicio al encuentro:

- Compañero, ¿no quiere hacer una pequeña introducción de por qué estamos acá reunidos? - dijo mirando a Miguel.

- Nosotros estamos interesados en esto de las cooperativas, queremos saber más, venimos a escuchar-respondió mientras se acomodaba en su silla.

A continuación, Andrea explicó qué es la CTEP, enfatizando que "es un sindicato que busca organizar y pelear por derechos laborales básicos para los trabajadores de la economía popular, los que no tienen patrón, los que trabajan en la calle o en sus casas". Luego se explayó en el recorrido que llevó al MTE a conformar los "Polos Textiles":

- Nosotros, cuando empezamos a militar con los trabajadores del sector, lo que empezamos a ver es que la mayoría trabajaba en sus casas en malas condiciones y que la imposibilidad de habilitar legalmente sus talleres familiares los dejaba en una situación muy vulnerable frente a la persecución de la policía y los inspectores, y a la explotación de los fabricantes y las marcas. Por eso decidimos armar los polos, que son espacios comunes de trabajo que permiten mejorar las condiciones de trabajo y seguridad, pero también negociar los precios en términos más favorables con los fabricantes y pelear por derechos. Para eso se alquila un galpón que luego se pueda habilitar y todos los trabajadores llevan sus máquinas e instrumentos de trabajo. En paralelo, se trabaja en conformar una cooperativa y que todos se inscriban en el Monotributo Social para que tengan aportes jubilatorios y accedan a nuestra obra social, la mutual Senderos, ${ }^{7}$ que es una obra social propia pensada para los trabajadores de la economía popular y que cubre el plan médico obligatorio. Además, todos los compañeros se inscriben en el Salario Social Complementario, ${ }^{8}$ que es un derecho conquistado por la CTEP, es un complemento salarial que mejora los ingresos de cada compañero. (Registro de campo, Buenos Aires, 11/8/2018)

Las palabras de Andrea sintetizaban la propuesta organizativa del MTE para el sector: la conformación de los "polos textiles", espacios comunes de trabajo que permitieron a los trabajadores trasladar sus actividades laborales fuera del hogar familiar. De allí que la principal bandera de la organización sea: "El polo para trabajar, la casa para habitar". Así, la conformación de la rama del movimiento y la federación de costureros de CTEP buscó proponer una forma de construcción política que no se limitara a la promoción de denuncias y la clausura de establecimientos, sino que ofreciera a los trabajadores una salida laboral digna y con derechos. En efecto, tras la creciente visibilización de
7. Para un análisis específico de la Mutual Senderos ver Bruno et al. (2017).

8. El Salario Social Complementario fue establecido por la Ley de Emergencia Social aprobada el 14 de diciembre de 2016. La sanción de esta ley fue promovida por la CTEP, Barrios de Pie y la Corriente Clasista y Combativa. Se trata de un complemento salarial mensual otorgado a los trabajadores de la economía popular. Ley 27.345 publicada en el Boletín Oficial el 23/12/2016. Recuperado dehttps:// www.boletinoficial.gob.ar/detalleAviso/primera/11514825/null. 
los denominados "talleres clandestinos", el Estado -y en particular el Gobierno de la Ciudad de Buenos Aires a través de la Agencia Gubernamental de Control- actuó intensificando los controles y la clausura de talleres, que dejaban a los trabajadores sin su única fuente de ingresos.

Desde que inicié mi investigación con los trabajadores costureros del MTE participé de numerosas reuniones como la que he relatado. Se trataba del primer paso hacia la conformación de un nuevo polo, al que le seguían usualmente dos o tres asambleas, luego de las cuales comenzaba la búsqueda de un galpón para alquilar. Cuando comencé mi trabajo de campo, a comienzos de 2016, había cuatro polos en funcionamiento. Desde entonces, el crecimiento fue exponencial: para septiembre de 2019 existían 26 polos, que reúnen a más de 800 trabajadores en toda el Área Metropolitana de Buenos Aires. El vínculo con el movimiento introdujo un nuevo horizonte de expectativas y proyecciones a futuro, centrado en la creación de los polos y la producción colectiva. Por supuesto que para muchos -aunque no para todos- el vínculo con organizaciones barriales o políticas no era algo nuevo en sus vidas, ya que tenían experiencias previas de organización barrial. Tal fue el caso del Polo Textil Miró, el primero en crearse. Fany, su fundadora y presidenta, suele afirmar que la "historia del polo empezó con la lucha por el barrio". En 2006, Fany y Margarita, que también es su vecina, habían conocido a los militantes del MTE, quienes habían acompañado a los vecinos durante la resistencia al desalojo y la demanda por la expropiación de las tierras en las que vivían. Desde entonces, forjaron una relación de confianza y afecto duradera que permitió la creación del polo años después.

El derrotero que siguió la multiplicación de los polos fue delineándose a partir de las relaciones familiares, comunitarias y de trabajo previas de quienes los integraban. Así, el armado de cada nuevo polo partía de ir convocando a estas reuniones a los conocidos de la colectividad, vecinos o familiares dedicados a la costura. Los trabajadores hicieron grandes esfuerzos para ahorrar y generar un fondo común que les permitiera solventar los gastos de alquiler, pero también arreglos edilicios como las instalaciones eléctricas, la adquisición de matafuegos, o incluso el equipamiento de la cocina y el comedor que compartirían cada día. Una vez alquilado el galpón y finalizados los arreglos, mudaron sus propias máquinas a los nuevos espacios de trabajo. Estos objetos condensaban las relaciones y experiencias previas de los trabajadores que se pusieron al servicio de la creación de los polos. Así por ejemplo, en el Polo Textil Miró, las primeras máquinas en ocupar el espacio fueron las de Mariela, hija de Fany y secretaria de la cooperativa. Mariela las había obtenido de uno de sus "patrones", que se las había entregado como medio de pago: el hombre le dio las máquinas y ella le "pagaba con trabajo". Hoy Mariela todavía recibe "cortes" de este hombre y los confecciona en la cooperativa junto con su "grupo de trabajo".

No se trata esta de una dinámica exclusiva del Polo Miró; la mayoría de los polos se organizaron en "grupos de trabajo" a partir de relaciones familiares o de confianza previas. Esto implicó que, dentro del lugar de trabajo, cada familia o grupo de afinidad continuó trabajando juntos cosiendo los "cortes" traídos por sus "patrones". Pero, además, desde el movimiento se propuso la realización de trabajos a mayor escala articulando la producción de varios polos textiles. En particular, dos órdenes de trabajo fueron especialmente significativas por su volumen: la producción de guardapolvos para el Ministerio de Desarrollo de Nación y la confección de la ropa de trabajo para los recicladores del Municipio de Lomas de Zamora.

Así, la creación de los polos se apoyó en -pero también reorientó- sus formas de producción y prácticas previas. En este sentido, la experiencia del Polo Unión y Libertad es muy significativa. A pocos meses de haberlo conformado, sus trabajadores se propusieron equiparlo con una mesa y una máquina de corte. La estrategia para conseguirlas fue 
incorporar a la cooperativa a un pasanako que estaban iniciando entre los trabajadores, es decir, incorporaron al polo como si fuera una persona más y pagaron su cuota mensual tomando el dinero del fondo común al que ellos mismos aportaban todos los meses. Decidieron que la cooperativa retiraría primero el pasanako para poder adquirir dichos instrumentos de trabajo sin demora. Resulta singular que, para estos trabajadores, el polo no era simplemente la suma de sus partes -o de cada uno de sus integrantes- sino que fue proyectado como una entidad plural, una entidad que coexistía de manera no contradictoria con sus dinámicas y formas previas de "ganarse de la vida".

\section{¿Qué produce un Polo Textil?}

La creación de los polos mejoró significativamente las condiciones de trabajo y los ingresos de los trabajadores. Pero además, muchos relatan este proceso como una construcción que "cambia la vida". Al decirlo enfatizan, por un lado, que ya no tienen "miedo". Así, durante una asamblea en un polo de Lomas de Zamora, Fany enfatizó: "En la casa pasábamos miedo, que la policía nos saque toda nuestra producción. Los polos también son una protección para los costureros". Por otro lado, suelen destacar el modo en que mudar las máquinas e instrumentos a los polos transformó sus hogares y les permitió disponer de mucho más espacio para hijos, pero también dejar de trabajar largas jornadas para disfrutar más tiempo en familia. En este sentido, resulta significativo el modo en que Cecilia, la esposa de Liders, me relató el cambio que significó en sus vidas la creación del polo en el que ahora trabajan cotidianamente. Me explicó que desde que "salieron de su casa" y obtuvieron la inscripción formal de la cooperativa pudieron acceder a trabajos directamente entregados por las fábricas y mejor pagos. Este cambio implicó una nueva organización del tiempo para ella

En casa trabajábamos para la feria. Y te piden que entregues el lunes, entonces, trabajas todo el sábado y domingo hasta la noche, muchas horas para poder cumplir. Ahora venimos al polo por la mañana y a las 5 me puedo ir a casa a estar con mis hijas. Los fines de semana podemos hacer cosas con ellas, antes no tenía tiempo. (Registro de campo, Cecilia, Buenos Aires, 23/3/2019)

Una tarde, mientras nos dirigíamos a hacer un trámite junto a una de las trabajadoras del polo, Fany le insistió: "Es muy grande la cooperativa, tenés que entender que es muy importante porque nos ayudamos entre nosotros" Registro de Campo, Fany, Buenos Aires, 24/8/2016). La insistencia de Fany venía a colación de una reciente rifa que habían organizado para juntar dinero para una costosa operación de su hijo. Aquella no fue la única vez; en numerosas oportunidades se organizaron para juntar el dinero necesario para ayudar a compañeros o a sus familias. Para ello se organizaban rifas o "polladas", ventas de comida para vecinos y conocidos. En muchos de los polos hicieron pasanakos o rondas -como preferían llamarlo los integrantes de la colectividad paraguaya- que solían utilizarse para solventar mejoras o ampliaciones en sus casas. Junto con la organización y sus militantes también acompañaron la internación de hijos con problemas de adicción o la asistencia a mujeres víctimas de violencia de género. Así, en la cotidianidad de los polos se producían prendas de vestir, trabajo y una remuneración económica para sus integrantes, pero también formas colectivas de atender a la reproducción de la vida y producir "bienestares", tomando los términos propuestos por María Inés Fernández Álvarez (2016).

En particular, el cuidado de los hijos ocupó un rol central. Se trataba de una de las preocupaciones principales de aquellas trabajadoras que se acercaban interesadas por los polos. Para estas mujeres, el trabajo en el propio domicilio era muchas veces la única salida para poder cumplir con las tareas de cuidado, pero también en pos de aportar ingresos para el sustento del núcleo familiar. En este sentido, el cuidado de los 
9. A partir de los resultados del relevamiento, las organizaciones participantes demandaron la realización de un plan nacional de integración sociourbana de los barrios, entendida como el acceso a servicios básicos (agua, luz y cloacas), alumbrado, transporte público, recolección de residuos, salud y educación. Para un análisis del RENABAP, ver Guevara, Marigo y Wallace (2018). niños fue, desde los inicios de la rama textil del MTE, una cuestión a resolver colectivamente en la medida que era condición de posibilidad para "salir de casa" a trabajar al polo. Los estudios feministas han señalado la injusta distribución de los cuidados y su invisibilización como trabajo no remunerado e históricamente feminizado (Carrasco, 2001; Beneria, 2006; Pérez Orozco, 2014). Para atender a esta desigualdad, desde el movimiento se pusieron en funcionamiento dos centros de cuidado y recreación infantil. Uno de ellos está ubicado en el barrio Gabriel Miró. Este centro de cuidado se construyó en un espacio comunitario que Fany ha venido sosteniendo desde los inicios del barrio y en el que ya funcionaban un apoyo escolar y un merendero. Tal como señalaron numerosos estudios, estos espacios comunitarios usualmente sostenidos por organizaciones sociales han sido centrales para garantizar la provisión del cuidado en sectores populares (Santillán, 2014; Zibecchi, 2014). A su vez, la creación de este centro de cuidado y recreación infantil puede ser conceptualizada como lo que algunas autoras han denominado "prácticas colectivas" o "compartidas" de cuidado que permiten la participación de mujeres en espacios de militancia, trabajo o incluso programas estatales (Fernández Álvarez y Pacífico, 2016; Sciortino, 2018; Pacífico, 2019). En este caso, el cuidado de los niños fue incorporado a las prácticas de organización gremial a partir de la construcción de los centros y definido como un derecho de los trabajadores, pero también de los niños y niñas.

En esta construcción colectiva para mejorar sus vidas, los barrios, la provisión de servicios como agua y luz, o incluso el acceso a la titularidad de la tierra, eran objeto de particular atención. Tal como señalaron algunas autoras, las condiciones urbanas y habitacionales pueden ser conceptualizadas en tanto "infraestructuras para el sostenimiento de la vida” (Vega, Paredes y Almeida, 2019) y, por lo tanto, parte sustantiva de la reproducción social. En esta dirección, para mis interlocutores cobró enorme relevancia la creación, en el año 2016, del Registro Nacional de Barrios Populares (RENABAP). Para ello se realizó un relevamiento que alcanzó a 4416 villas y asentamientos informales en todo el país y fue desarrollado por la CTEP, Barrios de Pie, la Corriente Clasista y Combativa, y la ONG Techo, en convenio con la Jefatura de Gabinete del gobierno nacional. Los propios habitantes de los barrios fueron los encargados de encuestar a sus vecinos y se les entregó un Certificado de Vivienda Familiar que fue destacado como un primer paso hacia la integración sociourbana de los barrios populares. ${ }^{9}$ El barrio Gabriel Miró fue el primero en ser relevado y los integrantes del Polo Textil Miró no solo participaron como censistas, sino que también fabricaron las pecheras que luego utilizaron los censistas de todo el país. Por aquellos días se desarrolló una asamblea en dicho polo, en la que el tema central de debate era la negativa por parte de algunos trabajadores de llevar sus máquinas y comenzar a trabajar en la cooperativa. A continuación, reproduzco el debate que se produjo en aquella oportunidad:

- Tenemos que estar orgullosos porque tener una cooperativa; es algo muy importante para nosotros, para nuestro barrio -explicó Fany-. Piensen que esta cooperativa no es para mí solo, es para todos, es para nuestros hijos el día de mañana que vayan creciendo con otra mentalidad. No que les digamos que tienen que estar solos ahí trabajando en la casa.

Delzy, hija de Margarita, agregó:

- La idea de la cooperativa también es generar unidad, generar conciencia y compañerismo. No fijarme solamente en mí, en lo que yo puedo hacer o ganar, sino generar unidad. Yo creo que muchos no valoran lo que tienen, no le dan el valor que se merece a estar en una cooperativa. Se fijan en sí mismos, si me conviene, el precio, y se olvidan de los demás compañeros, de cómo están, que capaz necesitan más que otros. 
Margarita había estado callada toda la reunión, observando desde un costado. Finalmente tomó la palabra:

- Aquí se habló de la cooperativa, del trabajo, todo. Pero esto no se trata de trabajo solamente. Una cooperativa quiere decir que nos cooperaremos, ahora no se trata de trabajo nomás. Muchos de ustedes no saben que están censando en el barrio. No es que como cooperativa estamos dejando al barrio de lado. ¿Cómo vamos a ir a reclamar por nuestro barrio sin los papeles? Entonces, como una cooperativa, tenemos que estar unidos. Nos estamos preparando para que no nos echen y que podamos ir y decir "mirá, aquí somos tanta gente". También los chicos de la CTEP están trabajando por el barrio, tenemos reuniones, vamos al municipio. (Registro de campo, Buenos Aires, 5/8/2016)

Durante aquella asamblea, los argumentos de estas mujeres a favor de fortalecer la cooperativa buscaron desplazar el foco de la expectativa de "éxito" en términos económicos clásicos -en tanto aumento de la remuneración o ganancia obtenida- para enfatizar la posibilidad de lograr mejoras en el barrio. Las tres mujeres apuntaban a que la cooperativa no tenía que pensarse como un beneficio "personal", sino en función de una colectividad que se expresaba bajo la idea de "unidad". Al decir que "no valoran lo que tienen", Delzy oponía muy claramente un argumento económico e individual ("ganaré más dinero") a un argumento que considerara el "compañerismo". Fany, en cambio, hacía énfasis en lo que aquella experiencia de organización implicaba en términos de legado para sus hijos, para que ellos "crezcan con otra mentalidad", en la que se priorice algo más allá del beneficio personal. En esta valoración, Margarita también traía una cuestión que para ella era central: el vínculo con los militantes, a quienes veía como parte integrante de la "unidad" a generar en la medida que ellos "trabajan por el barrio". Benoît de L’Estoile (2014) llamó la atención sobre la aparente irracionalidad de que los campesinos del nordeste brasileño con quienes trabajó afirmaran que "El dinero es bueno, pero un amigo es mejor". El autor propone comprender esta afirmación desplazando la mirada de la "economía" como marco de referencia para atender a las expectativas, experiencias y al universo de posibilidades en los cuales las personas crean condiciones para "vivir una buena vida". En esta dirección, y parafraseando al autor, para algunos de los trabajadores el dinero era bueno, pero la cooperativa era mejor.

En resumen, la construcción de los polos y de la organización gremial fue vivenciada y valorada por sus integrantes como una forma de construir "unidad", al tiempo que habilitó una diversidad de acciones en común para mejorar sus vidas: desde el sostenimiento de espacios comunitarios y la concreción de mejoras en sus barrios, la creación de los centros de cuidado y recreación infantil, pero también la organización de festejos por el Día del Niño, viajes de vacaciones o torneos de fútbol entre todos los integrantes de la rama. Así, las formas de lucha y los esfuerzos -individuales, familiares y colectivos- por construir una buena vida evidencian que la productividad de su labor excede lo que podría ser cuantificado a partir de un cálculo económico en sentido estricto. Pero, además, iluminan el sentido relacional de la construcción de "vidas que valen la pena ser vividas" (Narotzky y Besnier, 2014), una búsqueda en la que el trabajo o el progreso individual son inescindibles del bienestar para la familia y de la producción de prácticas y formas de organización comunitarias.

\section{Reflexiones finales}

A partir del trabajo de campo etnográfico desarrollado junto con los costureros y costureras del MTE-CTEP en estas páginas he propuesto analizar a la economía popular como plural. Retomando la propuesta de Narotzky y Besnier (2014), mi análisis puso de 
relieve la centralidad que tuvieron una multiplicidad de prácticas y relaciones a partir de las cuales estos trabajadores se "ganan la vida", tanto en los modos de acumulación del capital, como en las dinámicas de organización gremial y política que buscaron resistirlos. En este sentido, señalé que las relaciones de vecindad, familiares y entre paisanos marcaron el modo en que estos trabajadores se incorporaron a la industria textil tercerizada como los eslabones más débiles de la cadena. Lejos de ser actores pasivos de sus circunstancias, han logrado transformar en base para la organización colectiva y gremial dichas relaciones y prácticas que previamente constituían un recurso capitalizable para las cadenas de valor de la industria. A su vez, mostré que esta particular forma de organización gremial articuló el trabajo productivo y el desarrollo de formas colectivas de reproducción de la vida en un sentido amplio, que incluyeron la lucha por mejoras en los barrios, prácticas de cuidado, ayuda mutua y actividades de recreación.

Para finalizar, quisiera destacar que conceptualizar a la economía popular como plural abre pistas para desanaturalizar la idea de que la economía constituye una única forma de acción social centrada en el cálculo, o un único tipo de valor definido por el mercado. Como señalé, para mis interlocutores, la economía popular no solo produce valor en términos mercantiles o monetarios, sino una diversidad de valores. Este análisis dialoga con recientes estudios etnográficos que han puesto en cuestión que el mercado sea el único árbitro y productor de valor (Collins, 2017). En particular, David Graeber (2018) ha propuesto entender al valor no solo como valor económico y remuneración en los términos en los que usualmente se lo considera, sino como producción de proyectos significativos para las personas. Así, llamó la atención sobre el hecho de que el sistema de valor de cambio nos ha llevado a creer que solo ciertas formas de trabajo -el trabajo asalariado o aquel que produce mercancías- producen valor. En el mismo sentido, Benoît de L'Estoile (2014) señaló que los esfuerzo para "vivir y vivir bien" son mejor comprendidos si atendemos a los horizontes de expectativas en los que el valor de mantener relaciones sociales desafía los marcos de referencia basados en el cálculo monetario que solemos asociar a la economía moderna. Este artículo muestra que los polos no fueron solo entendidos como un medio para generar un ingreso en dinero, sino también -y de manera no contradictoria- como una apuesta para construir "unidad" y sostener formas de organización que buscan mejorar la vida junto a familiares, paisanos, vecinos y compañeros. Así, las prácticas, relaciones e iniciativas que desarrollaron como parte de esta organización -condensadas en la creación de los polos textiles- tensionan las dicotomías asumidas entre producción/reproducción, cálculo/ desinterés, política/economía.

En síntesis, la noción de pluralidad propuesta da cuenta tanto de las condiciones actuales de las economías populares, como también del valor de su producción cotidiana, y permite poner en cuestión los prejuicios y estigmas contenidos en la imagen de la víctima-esclavo con la que suele desvalorizarse a los trabajadores costureros. En esta dirección, este trabajo es una invitación a repensar la economía, pero también la industria, reconociendo el valor y la potencia productiva de los trabajadores y las organizaciones como la CTEP. Solo así podremos imaginar y construir formas de producción y reproducción de la vida en las que los conocimientos, deseos y aspiraciones plurales de los trabajadores sean los protagonistas. 


\section{Sobre la autora}

Doctora en Antropología Social de la Universidad de Buenos Aires y la École des Hautes Études en Sciences Sociales. Docente de la carrera de Ciencias Antropológicas, UBA. Participa de distintos proyectos colectivos de investigación y extensión universitaria bajo la dirección de María Inés Fernández Álvarez.

\section{Financiamiento}

Esta investigación fue financiada por una beca posdoctoral del CONICET. Asimismo, forma parte de dos proyectos de investigación colectivos: Proyecto PICT “Prácticas políticas colectivas, modos de gobierno y vida cotidiana: etnografía de la producción de bienes, servicios y cuidados en sectores subalternos" 2016-2019, Agencia Nacional de Promoción Científica y Tecnológica; Proyecto UBACYT “Prácticas políticas colectivas, modos de agremiación y experiencia cotidiana: etnografía de prácticas de organización de trabajadores de sectores populares”, Programación 2018-2021, Instituto de Ciencias Antropológicas, FFYL, UBA. Ambos proyectos son dirigidos por la Dra. María Inés Fernández Álvarez.

\section{Agradecimientos}

A mis compañeros del equipo de investigación, y en especial a mi directora, María Inés Fernández Álvarez, por el diálogo y la reflexión colectiva sostenidos en todos estos años. Aunque lo volcado en estas páginas es de mi entera responsabilidad, no hubiera sido posible sin la práctica de "pensar juntos/as". 


\section{Q Referencias bibliográficas}

》 Abal Medina, P. (2017). Los movimientos obreros organizados en Argentina (2003-2016). En P. Abal Medina, A. Natalucci y F. Rosso (Comps.). ¿Existe la clase obrera? (pp. 21-61). Buenos Aires: Capital Intelectual.

»Adúriz, I. (2009). La Industria Textil en Argentina. Su evolución y sus condiciones de trabajo. Buenos Aires: FOCO - Foro Ciudadano de Participación por la Justicia y los Derechos Humanos del Instituto para la Participación y el Desarrollo (INPADE).

"Arcos, M. A. (2013). “Talleres clandestinos": el traspatio de las "grandes marcas". Organización del trabajo dentro de la industria de la indumentaria. Cuadernos de Antropología, 10, 333-351.

"Benencia, R. (2009). El infierno del trabajo esclavo: La contracara de las "exitosas" economías étnicas. Avá, 15, 1-32.

»Beneria, L. (2006). Trabajo productivo/reproductivo. Pobreza y políticas de conciliación. Nómadas 24, 8-21.

"Brooks, A. (2015). Clothing poverty: the hidden world of fast fashion and second-hand clothes. Londres: Zed Books.

" Bruno, D., Coelho, R. y Palumbo, M. M. (2017). Innovación organizacional e institucionalización conflictiva de las organizaciones de la economía popular. El caso de la Confederación de Trabajadores de la Economía Popular (CTEP). Argumentos, 19, 90-119.

" Calvelo, L. (2012). La migración internacional en Argentina hacia 2010. Revista Interdisciplinar da Mobilidade Humana, 20(39), 135-157.

»Campbell, S. (2018). Border capitalism, disrupted: precarity and struggle in a Southeast Asian industrial zone. Ithaca: Cornell University Press.

»Carbonella, A. y Kasmir, S. (2015). Dispossession, disorganization and the anthropology of labour. En J. G. Carrier y D. Kalb (Eds.), Anthropologies of class: Power, practice, and inequality (pp. 102-117). Cambridge: Cambridge University Press.

"Carrasco, C. (2001). La sostenibilidad de la vida humana: ¿un asunto de mujeres? Mientras Tanto, 82, 43-70.

"Castronovo, A. (2018). ¡Costureros carajo! Trayectorias de lucha y autogestión en las economías populares argentinas. Íconos. Revista de Ciencias Sociales, 62, 119-139.

»Collins, J. (2007). The rise of a global garment industry and the reimagination of worker solidarity. Critique of Anthropology, 27(4), 395-409.

"Collins, J. L. (2017) The politics of value: Three movements to change how we think about the economy. Chicago: University of Chicago Press.

》 de L'Estoile, B. (2014). Money Is Good, but a Friend Is Better. Current Anthropology, $55\left(\mathrm{~S}_{9}\right), \mathrm{S}_{62}-\mathrm{S}_{73}$.

》Denning, M. (2011). Vida sin salario. New left review, 66, 77-94.

» Fernández Álvarez, M. I. (2016). Experiencias de precariedad, creación de derechos y producción colectiva de bienestar(es) desde la economía popular. Ensambles en sociedad, política y cultura, 4 y 5, 72-89. 
»Fernández Álvarez, M. I. (2020). Building from heterogeneity: the decomposition and recomposition of the working class viewed from the "popular economy" in Argentina. Dialectical Anthropology, 44, 57-68. doi: 10.1007/s10624-018-9509-6

»Fernández Álvarez, M. I. y Carenzo, S. (2012). “Ellos son los compañeros del CONICET”. El vínculo con organizaciones sociales como desafío etnográfico. Publicar, 12, 9-34.

»Fernández Álvarez, M. I. y Pacífico, F. (2016). Cuidados, trabajo y formación. Reflexiones a partir de una etnografía sobre programas de "inclusión social” destinados a cooperativas de mujeres. En V Encuentro Internacional de Investigación de Género. Universidad Nacional de Luján, Luján, Argentina.

» Gago, V. (2014). La razón neoliberal: economías barrocas y pragmática popular. Buenos Aires: Traficantes de sueños.

» Gago, V. y Mezzadra, S. (2015). Para una crítica de las operaciones extractivas del capital: Patrón de acumulación y luchas sociales en el tiempo de la financiarización. Nueva sociedad, 255, 38-52.

» Graeber, D. (2018). Hacia una teoría antropológica del valor. México: Fondo de Cultura Económica.

» Guevara, T., Marigo, P. y Wallace, J. (2018). Integración urbana y políticas públicas: el caso del registro nacional de barrios populares de Argentina: decreto $n^{\circ} 358 / 2017$. Oculum Ensaios, 15(3), 455-473.

» Halpern, G. (2005). Neoliberalismo y migración: paraguayos en Argentina en los noventa. Política y cultura, 23, 67-82.

» Kalb, D. (2015). Introduction: class and the new anthropological holism. En J. G. Carrier y D. Kalb (Eds.). Anthropologies of class: Power, practice, and inequality (pp. 1-27). Cambridge: Cambridge University Press.

» Lieutier, A. (2010). Esclavos: Los trabajadores costureros en la Ciudad de Buenos Aires. Buenos Aires: Retórica Ediciones.

» Lomnitz, L. A. (1993). Cómo sobreviven los marginados. México DF: Siglo XXI.

» Montero, J. (2012). La moda neoliberal: El retorno de los talleres clandestinos de costura. Geograficando, 8(8), 19-37.

» Munck, R. (2013). The Precariat: a view from the South. Third World Quarterly, 34(5), 747762.

» Muñoz, M. A. (2019). Voluntades populares, voluntades laborales: el caso de la Confederación de los Trabajadores de la Economía Popular. Trabajo y sociedad: Indagaciones sobre el empleo, la cultura y las prácticas políticas en sociedades segmentadas, 32, 479-510.

» Narotzky, S. y Besnier, N. (2014). Crisis, Value, and Hope: Rethinking the Economy. Current Anthropology, 55(S9), S4-S16.

» Natalucci, A., y Morris, B. M. (2019). ¿Superando la fragmentación? Un análisis de las estrategias de articulación entre la CGT y la CTEP (2009-2017). Astrolabio, 23, 169-197.

»Pacecca, M. I. y Courtis, C. (2008). Inmigración contemporánea en Argentina: dinámicas y políticas. Serie población y desarrollo (84), 1-72. Informe elaborado para el Centro Latinoamericano y Caribeño de Demografía (CELADE), División de Población de la Comisión Económica para América Latina y el Caribe (CEPAL).

»Pacífico, F. (2019). Producir la política desde las casas. Etnografía de procesos de organización colectiva de mujeres titulares de programas estatales. (Tesis de doctorado). Universidad de Buenos Aires, Facultad de Filosofía y Letras, Ciudad Autónoma de Buenos Aires, Argentina. 
"Pérez Orozco, A. (2014). Subversión feminista de la economía. Aportes para un debate sobre el conflicto capital-vida. Madrid: Traficantes de sueños.

» Rivera Cusicanqui, S. (2011). Teoría del agua sucia. Diálogo con Silvia Rivera Cusicanqui. En Colectivo Simbiosis y Colectivo Situaciones (Eds.). De chuequistas y overlockas. Una discusión en torno a los talleres textiles (pp. 17-34). Buenos Aires: Tinta Limón.

» Salgado, P. D. (2012). El trabajo en la industria de la indumentaria: una aproximación a partir del caso argentino. Trabajo y sociedad, 16(18), 59-68.

»Santillán, L. (2014). El cuidado y la educación infantil en experiencias comunitarias. Un análisis antropológico. Educação, Sociedade \& Culturas, 41, 91-108.

" Sciortino, S. (2018). Una etnografía sobre arreglos familiares, leonas y mujeres superpoderosas. Prácticas compartidas entre las titulares del ‘Ellas Hacen'. Cuadernos de Antropología Social, 48, 55-71.

"Vega, C., Paredes, M., y Almeida, A. N. (2019). Desigualdades y crisis reproductiva tras el terremoto en la costa ecuatoriana. Estrategias familiares ante el modelo de desarrollo y trabajo extractivo. AlBR: Revista de Antropología Iberoamericana, 14(2), 323-350.

»Zelizer, V. (2009). La negociación de la intimidad. Buenos Aires: Fondo de Cultura Económica.

»Zibecchi, C. (2014). Cuidadoras del ámbito comunitario: entre las expectativas de profesionalización y el 'altruismo'. Íconos, 50, 129-145. 